\title{
Expression of NCAM-H and S100 Protein in the Rostral Migratory Stream of the Adult Guinea Pig Forebrain
}

\author{
A. T. M. Shariful Islam, Keiichiro Nakamura and Masaru Kawabuchi \\ Department of Anatomy, Faculty of Medicine, Kyushu University, Fukuoka 812-82
}

Received for publication March 1, 1997 and in revised form April 10, 1997

We demonstrated a double-labeled immunofluorescent cytochemistry under confocal laser scanning microscope, using antibodies against highly polysialylated isoform of neural cell adhesion molecule (NCAM-H), and $\mathrm{Ca}^{++}$binding astroglial marker in the brain, S100 protein (S100) in the rostral migratory stream (RMS) of the subependymal layer (SEL) of the adult guinea pig forebrain. In the adult olfactory system, NCAM-H is considered to be associated with the continuous generation and growth of granule cells. In the whole length of germinal SEL, varied populations of blast like, beaded, clustered NCAM-H positive elements were densely intermingled with typical astrocytic subpopulations of $\mathbf{S} 100$ protein. Some especialized phenotypes of S100 immunopositive ependymoglial tanycytes gave off their basal processes into NCAM-H immunopositive clusters in the rostral extention of subependymal zone (SEZ-re). Our results evinced the complex morphological multitude of neuro-glial (neuronal and neuroglial) coherence in the course of tangential migration of neuronal progenitors in the young adult guinea pig RMS.

Key words: Neural cell adhesion molecule, Polysialic acid, S100 protein, Migration, Confocal Laser scanning microscope

\section{Introduction}

The subependymal layer (SEL) extends caudally from the subventricular zone (SVZ), near the anterior horn of the lateral ventricle (SVZa) to rostrally the subependymal zone (SEZ), around the oblitereted olfactory ventricle, functioning as a type of "brain marrow" due to its ability to produce neuronal precursors throughout the life of an animal [1, 13, 20, 21]. Most of the interneuron precursors are generated postnatally in SVZa in rodents $[3,5,6,9]$. These precursors migrate tangentially to the olfactory bulb (OB) through a distinct rostral pathway, the rostral migratory stream (RMS) in SEL, and then proceed radially to reach their final destination in the different layers of $\mathrm{OB}$ $[6,7,11,12]$.

The neural cell adhesion molecule (NCAM), par-

Correspondence to: Dr. A. T. M. Shariful Islam, Department of Anatomy, Faculty of Medicine, Kyushu University, Maidashi 3-1-1, Fukuoka 812-82, Japan. ticularly its highly polysialylated moiety, is considered to be the specific molecular candidate that showed persistent expression in certain central neuronal centres related to adult neurogenesis [10, 11]. The polysialic acid (PSA) residues counteract the adhesive properties of NCAM molecules and thus play a crucial role in the tangential migration of neuroblasts in RMS, by attenuating the degree of adhesivity between cells [2, 4, 18, 19, 22].

Recently, the role of astrocytes in the tangential migration of neuronal progenitors has been examined by the subsequent studies in mice forebrain $[8,21]$. Schäfer and Heizmann also vividly reviewed the polyphasic roles of a $\mathrm{Ca}^{++}$binding acidic protein and brain astrocyte marker, S100 protein, which produces extracellular matrix (ECM) molecules, enhances chemotactic activity, and thereby evokes the process of neurite extention [17].

There are several immunohistochemical reports showing merely the ensheating role of astrocytes for the migrating neuroblasts in the subependymal proliferative zone of the different species of the adult rodents $[7,8$, 
11]. But so far as we are concerned, this is the first report on the adult guinea pig forebrain, where we have precisely compared the expression of migrating neuroblasts against the highly PSA residues of NCAM with the brain-astrocytic marker, S100 protein, to reveal the morphological configuration of neuro-glial coherence in the tangential migration of SEL.

\section{Materials and Methods}

Three to six weeks old five adult Hartley guinea pigs of either sex, weighing between 250 and $300 \mathrm{~g}$ were deeply anaesthetised with diethylether and perfused transcardially with $0.02 \mathrm{M}$ phosphate-buffered saline ( $\mathrm{pH}$ 7.4) followed by a fixative containing $1 \%$ paraformaldehyde in $0.1 \mathrm{M}$ sodium phosphate buffer ( $\mathrm{pH}$ 7.4). The brain was then blocked by stereotomy (Narishige Co., Japan), removed, and immersed into cold $\left(4^{\circ} \mathrm{C}\right)$ phosphate buffer solution containing 30\% sucrose. After 2-4 days, the blocks were transferred into cold isopentane and preserved in a deep freezer $\left(-80^{\circ} \mathrm{C}\right)$ till cutting. For the anterior forebrain, $50 \mu \mathrm{m}$ coronal sections were cut on a freezing microtome. The double immunofluorescent procedure consisted of incubating the preparations in a monoclonal mouse antibody against NCAM-H (mAb 12E3), and a polyclonal rabbit antiserum raised in bovine brain against $\mathrm{S} 100$ protein (Nichirei, Tokyo, Japan) at a dilution of $1: 1250$, and $1: 100$ in $0.02 \mathrm{M}$ sodium phosphate buffer solution (pH 7.4) containing $0.3 \%$ bovine serum albumin, $0.2 \%$ sodium azide, and $0.3 \%$ Triton $\mathrm{X}-100$ for 3 to 5 days at $4^{\circ} \mathrm{C}$ respectively. The binding of anti-NCAM-H antibody was detected by fluorescin conjugated mu-chain specific anti-mouse IgM $(1: 200)$, and anti-S100 protein by indirect immunofluorescence using biotinylated second layer of goat anti-rabbit IgG $(1: 400)$, followed by streptavidin texas red $(1: 200)$ for $2 \mathrm{hr}$ and then the sections were washed in PBS before being mounted in Vectashield mounting medium for fluorescence (vector labs). The controls for immunostaining included phosphate-buffered saline instead of the primary antiserum. They showed no immunolabeling. To reveal the double-labeled immunofluorescent contrast between NCAM-H and S100 protein, all the sections were examined in laser scanning confocal microscope (Olympus LSM-GB200).

\section{Results}

Examination of the coronal sections of guinea pig forebrain showed that NCAM-H positive cells in SEZ were frequently organized into clusters (Figs. 1, 2A). A punctate reaction with irregular cellular margin characterized the immature profile of the immunolabeling, but when the cells were closely packed, the immunolabel was so intense that it often masked the cellular details (Fig. 2A).

Most of the NCAM-H immunoreactive cells were restricted to the lateral wall as well as in the dorsal and ventral pole of the lateral ventricle (LV); the medial wall of the ventricle appeared free of label. The immonoreactive cells constituted a layer of one or two cells thickness towards the roof, floor and proximal to the ventral pole of the lateral wall of LV (Fig. 1b). Nevertheless, we frequently did note immunoreactive cells, alone or organized in small clusters, adjacent to the lateral wall of LV.

In the caudopallial angle of LV, the staining density revealed strong rather than adjacent parenchyme. The focal clusters of NCAM-H immuoreactive cellular elements seemed to be encased in $\mathrm{S} 100$ positive cellular elements in SVZ (Fig. 1a); but in the rostral part of SVZ (SVZ-rp), the focal arrangement of neuronal clusters turned into neuro-glial lineage along with closely apposed astrocytes in the lateral wall of LV (Fig. 1b).

SEZ-re formed the narrowest strip in SEL, where we found meticulous S100 protein like immunoreactivities and which constitute a special interlaced region with NCAM-H positive neuronal elements in the granule cell regeneration pathway. The fenestrated ependymal cells
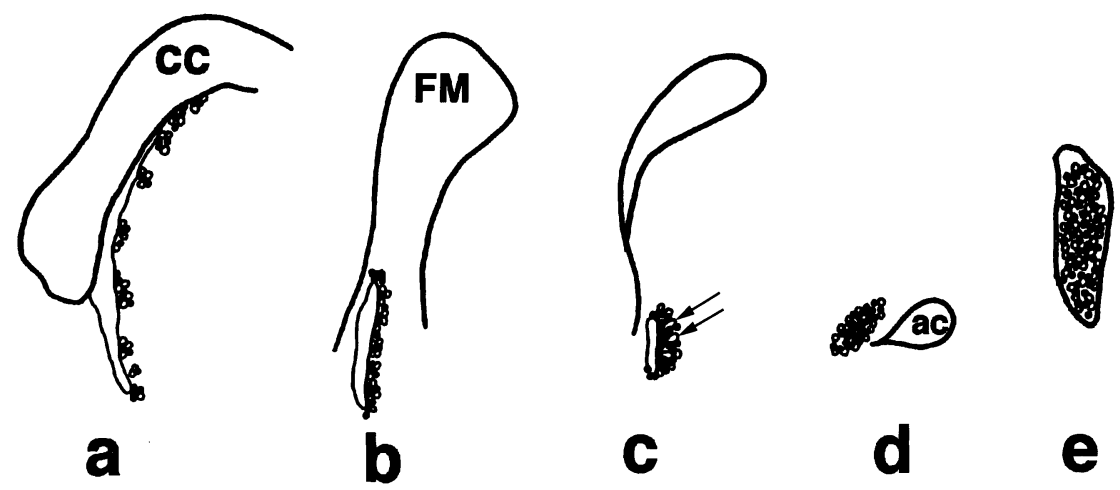

Fig. 1. Computer-generated schematic drawing of the representative coronal sections illustrating spatial shifting of neuro-glial coherence in the different levels of SEL showing a. in SVZa, focal clusters; b. in SVZ-rp, neuro-glial lineage along the lateral wall of LV; c. in SEZ-re, tanycytes and their basal projections into neuronal clusters; d. in SEZ-ob, neuro-glial core-shell arrangement; and e. in SEZ-rp, closely apposed neuroglial intermingling. Neuronal precursor (black dot); astrocytic phenotype (blank dot); tanycyte (elongated blank loop marked by arrows, as seen only in Fig. 1c); CC, corpus callosum; ac, anterior commissure; FM, forceps minor corpus callosum. 

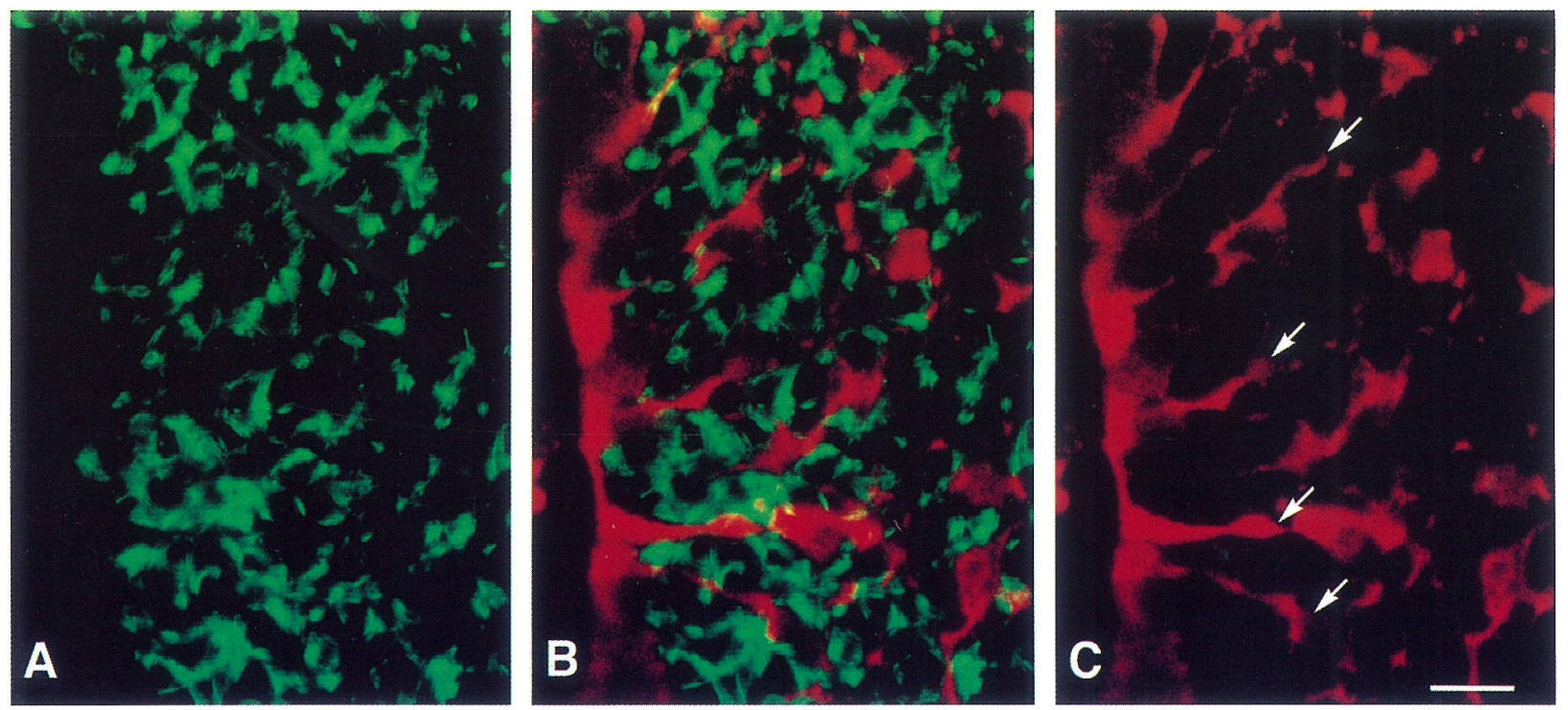

Fig. 2. Immunoflurescent confocal image of SEZ-re after incubation with A. antiserum against NCAM-H (green), C. anti-S100 protein (red); and $\mathbf{B}$. double-labeled immunoexpression between NCAM-H and S100 protein showing several projections of the basal processes of especialized ependymoglial cells, tanycytes (arrows) into the densely packed clusters of OB-interneuron precursors. $B a r=10 \mu \mathrm{m}$.

Table 1. Morphological multitude of neuro-glial coherence in RMS

\begin{tabular}{ll}
\hline Distribution & \multicolumn{1}{c}{ Morphology } \\
\hline SVZa & $\begin{array}{l}\text { focal neuronal clusters were enwrapped } \\
\text { in astrocytic immunopositive elements } \\
\text { neuronal clusters along with the apposed } \\
\text { astrocytes formed a neuro-glial lineage in } \\
\text { the lateral wall of lateral ventricle } \\
\text { especialized astrocytic phenotype, } \\
\text { tanycytes projected into densely packed } \\
\text { neuronal clusters } \\
\text { astrocytes were gradually shifted into the } \\
\text { outer shell, whereas neuronal clusters } \\
\text { were accumulated in the inner core } \\
\text { neuronal precursors and astrocytic } \\
\text { populations were closely apposed and in- } \\
\text { termingled with each other }\end{array}$ \\
\hline
\end{tabular}

were frequently stained with anti-S100 antisera and many of these cells were tanycytes, the especialized ependymal astrocytes, projecting their basal processes into NCAM-H immunostained cellular clusters particularly along the lateral wall of SEZ-re (Fig. 2-B, C).

In the intrabulbar part of SEZ (SEZ-ob), spatial arrangement of neuro-glial corelation was being shifted. Neuronal precursors stained against anti-NCAM-H antisera were gradually accumulated in the central core, where S100 immunopositive astroglial elements constituted a scaffold in the outer shell of SEZ-ob (Fig. 1d).

Finally, this core-shell neuro-glial morphology, as seen in the figure 1(d-e) turned into a closely apposed interlaced configuration in the rostral pole of SEZ (SEZ-rp), from where interneuron precursors leave off RMS, migrate radially, and differentiate into granule cells in the different layers of $\mathrm{OB}$.

\section{Discussion}

A great deal of attention is presently focused on the adult neurogenesis of granule cells [3, 9], and their tangential migration in RMS [7, 11]. Evidence from subsequent studies suggest the crucial role of NCAM-H and its PSA mediated interactions in the migration of olfactory interneuron progenitors in RMS $[9,10,22]$. Several attempts have been made to unveil the astrocytic role in the neuronal migration in SEZ $[8,17,21]$. All of these observations taken together suggest two possiblities: there may be an independent process of migration of neuroblasts irrespective of a defined substrate; and/or, the chain of neuronal progenitors migrate along an as yet undescribed substrate [11, 14-16, 21]. Although Lois et al. showed the predominant role of the processes of glial cells to enwrap the chains of migrating neuroblasts, through the examination of RMS at the electron microscopic level in mice forebrain [8], the astroglial role in the tangential dispersal of neuronal precursors has yet to be determined.

The intriguing configurations of spatio-temporal shifting of neuro-glial arrangement in the different parts of SEL, as we summarized in Table 1., showed a great deal of species differences. Those accord as well as contrast with the several previous investigations. The core-shell neuroglial configuration in guinea pig SEZ-ob is consistent with the previous study in mice forebrain [8], but focal clusters 
in SVZa, neuro-glial lineage in SVZ-rp, tanycyte projections into neuronal clusters in SEZ-re, and neuro-glial intermingling in SEZ-rp indicate an inextricable intricacy of tangential migratory process in RMS. Moreover, the fenestrated tanycytes and clustered neuronal coupling showed spatial specificity only in SEZ-re, which may constitute special permissive environment by which astrocytederived growth factors, trophic factors, ECM molecules as well as other biogenic substances can reversibly encompass through the neuronal, vascular and cerebrospinal fluid compartments and thereby facilitate the ultimate neuronal migration through cell-cell and cell-substrate interactions.

As any relevant approach to adult neurogenesis might be tangible to the adult mammalian brain repair, we showed for the first time the morphological multitude of general and especial neuro-glial coherence in RMS; and in contrast to the other species of rodents, the migration of SVZ cells to the $O B$ in guinea pig forebrain could serve as a model system to accelerate future study of the factors that control continued nonradial neuronal dispersion, even in adults.

\section{Acknowledgments}

The authors thank T. Seki for providing NCAM-H antibody (mAb 12E3). This work was supported by a Grant-in Aid for Scientific Research (No. 08670020) from the Ministry of Education, Science and Culture, Japan.

\section{References}

1. Altman, J.: Autoradiographic and histological studies of postnatal neurogenesis IV. Cell proliferation and migration in the anterior forebrain, with special reference to persisting neurogenesis in the olfactory bulb. J. Comp. Neurol. 137; 433-458, 1969.

2. Bonfanti, L. and Theodosis, D. T.: Expression of polysialylated neural cell adhesion molecule by proliferating cells in the subependymal layer of the adult rat, in its rostral extension and in the olfactory bulb. Neuroscience 62; 291-305, 1994.

3. Corotto, F.S., Henegar, J. A. and Maruniak, J. A.: Neurogenesis persists in the subependymal layer of the adult mouse brain. Neurosci. Lett. 149; 111-114, 1993.

4. Hu, H., Tomasiewicz, H., Magnuson, T. and Rutishauser, U.: The role of polysialic acid in migration of olfactory bulb interneuron precursors in the subventricular zone. Neuron. 16; 735-743,1996.

5. Kaplan, M. S. and Hinds, J. W.: Neurogenesis in the adult rat: electron microscopic analysis of light radioautographs. Science 197; 1092-1094, 1977.

6. Kishi, K.: Golgi studies on the development of granule cells of the rat olfactory bulb with reference to migration in the subepen- dymal layer. J. Comp. Neurol. 258; 112-124, 1987.

7. Lois, C. and Alverez-Buylla, A.: Long-distance neuronal migration in the adult mammalian brain. Science 264; 1145 1148, 1994.

8. Lois, C., Gracía-Verdugo, J.M. and Alverez-Buylla, A.: Chain migration of neuronal precursors. Science 271; 978981, 1996.

9. Luskin, M. B.: Restricted proliferation and migraton of postnatally generated neurons derived from the forebrain subventricular zone. Neuron. 11; 173-189, 1993.

10. Ono, K., Tomasiewicz, H., Magnuson, T. and Rutishauser, U.: N-CAM mutation inhibits tangential neuronal migration and is phenocopied by enzymatic removal of polysialic acid. Neuron. 13; 595-609, 1994.

11. O'Rourke, N. A.: Neuronal chain gangs: homotypic contacts support migration into the olfactory bulb. Neuron. 16; 10611064, 1996.

12. Peñafiel, A., Gutiérrez, A., Martín, R., Pérez-Cañellas, M. M. and Calle, A. D. L.: A tangential neuronal migration in the olfactory bulbs of adult lizards. NeuroReport. 7; 1257-1260, 1996.

13. Privat, A. and Leblond, C. P.: The subependymal layer and neighboring region in the brain of the young rat. J. Comp. Neurol. 146; 277-302, 1972.

14. Rousselot, P., Lois, C. and Alverez-Buylla, A.: Embryonic (PSA) N-CAM reveals chains of migrating neuroblasts between the lateral ventricle and the olfactory bulb of adult mice. $J$. Comp. Neurol. 351; 51-61, 1995.

15. Rutishauser, U.: NCAM and its polysialic acid moiety: a mechanism for pull/push regulation of cell interactions during development? Development. (suppl.) 116; 99-104, 1992.

16. Rutishauser, U., Acheson, A., Hall, A. K., Mann, D. M. and Sunshine, J.: The neural cell adhesion molecule (NCAM) as a regulator of cell cell interactions. Science 240; 53-57, 1988.

17. Schäfer, B. W. and Heizmann, C. W.: The S100 family of EFhand calcium binding proteins: functions and pathology. TiBS. 21; 134-140, 1996.

18. Seki, T. and Arai, Y.: Expression of highly polysialylated NCAM in the neocortex and piriform cortex of the developing and adult rat. Anat Embryol. 184; 395-401, 1991.

19. Seki, T. and Arai, Y.: Distribution and possible roles of the highly polysialylated neural cell adhesion molecule (NCAM-H) in the developing and adult central nervous system. Neurosci. Res. 17; 265-290, 1993.

20. Smart, I.: The subependymal layer of the mouse brain and its cell production as shown by radioautography after thymidine$\mathrm{H}^{3}$. J. Comp. Neurol. 116; 325-347, 1961.

21. Thomas, L. B., Gates, M. A. and Steindler, D. A.: Young neurons from the adult subependymal zone proliferate and migrate along an astrocyte, extracellular matrix-rich pathway. Glia. 17; 1-14, 1996.

22. Tomasiewicz, H., Ono, K., Yee, D., Thompson, C., Goridis, C., Rutishauser, U. and Magnuson, T.: Genetic deletion of a neural cell adhesion molecule variant (N-CAM-180) produces distinct defects in the central nervous system. Neuron. 11; 1163-1174, 1993. 